Original Research Paper

\title{
Aerosol route as a feasible bottom-up chemical approach for up-converting phosphor particles processing
}

\author{
I. Dugandžić ${ }^{a}$, V. Lojpur ${ }^{\text {a }}$, L. Mančić ${ }^{a}$, M.D. Dramićanin ${ }^{\text {b }}$, M.E. Rabanal ${ }^{\text {c }}$, T. Hashishin ${ }^{\text {d }}$, Z. Tan ${ }^{\text {d }}$, \\ S. Ohara ${ }^{\mathrm{d}}$, O. Milošević ${ }^{\mathrm{a}, *}$ \\ a Institute of Technical Sciences of SASA, K. Mihailova 35/IV, 11000 Belgrade, Serbia \\ ${ }^{\mathrm{b}}$ Vinca Institute of Nuclear Sciences, University of Belgrade, 11001 Belgrade, Serbia \\ ${ }^{\mathrm{c}}$ University Carlos III, Avd. Universidad 30, 28911 Leganes, Madrid, Spain \\ ${ }^{\mathrm{d} J o i n i n g}$ and Welding Research Institute, Osaka University, 11-1 Mihogaoka, Ibaraki, Osaka 567-0047, Japan
}

\section{A R T I C L E I N F O}

\section{Article history:}

Received 28 September 2012

Received in revised form 25 February 2013

Accepted 27 February 2013

Available online 24 March 2013

\section{Keywords:}

Aerosol

Yttrium oxide

Morphology

Phosphors

Up-conversion

\begin{abstract}
A B S T R A C T
The opportunities of the hot wall aerosol synthesis, i.e. conventional spray pyrolysis (CSP) method are demonstrated for the generation of highly spherical three-dimensional (3D) nanostructured phosphor particles with uniformly distributed components, phases and nano-clustered inner structure. With the presumption that certain particle morphology is formed during the evaporation/drying stage, the aerosol transport properties and powder generation are correlated with the particles structural and morphological features. With the help of various analyzing techniques like Field Emission Scanning Electron Microscopy (FE-SEM), Transmission Electron Microscopy (TEM) coupled with energy dispersive X-ray Analysis and STEM mode (TEM/EDS), X-ray Powder Diffraction (XRPD) and fluorescence measurements the feasible processing of up-conversion rare-earth $\mathrm{Y}_{2} \mathrm{O}_{3}: \mathrm{Er}$, Yb phosphors powders are discussed.

(c) 2013 The Society of Powder Technology Japan. Published by Elsevier B.V. and The Society of Powder Technology Japan. All rights reserved.
\end{abstract}

\section{Introduction}

Rare-earth based up-converting phosphor (UCP) nanocrystalline particles represent the new, sophisticated generation in materials science and engineering with the potential use in modern display and labeling technologies, sensors, optical data storage, telecommunications, etc. [1-5]. They exhibit the unique property of emitting visible light following photoexcitation in near infrared region. The most efficient up-converting host materials belong to the group of the yttrium based- inorganic compounds like fluorides, oxides and oxysulfides codoped with the trivalent rare earths $\left(\mathrm{Yb}^{3+}, \mathrm{Er}^{3+}, \mathrm{Tm}^{3+}, \mathrm{Pr}^{3+}, \mathrm{Ho}^{3+}\right.$, etc.). Among other yttrium compounds, yttrium oxide represents an efficient UCP phosphor host material for the substitution of rare earth ions because of its low phonon energy, $<600 \mathrm{~cm}^{-1}$, broad optical transparency range $0.2-$ $8 \mu \mathrm{m}$, high refractive index, $>1.9$ and large energy band-gap, $5.8 \mathrm{eV}$ [6]. Yttrium oxide posses a cubic crystal structure with a space group, S.G. Ia3-( $\left.\mathrm{T}_{h}^{7}\right)$ in which there are two crystallographically different rare-earth sites, C2 (75\%) and S6 (25\%); by that, a unit cell is composed of four atom positions, three having a point symmetry C2 and one position with a point symmetry S6 [7].

\footnotetext{
* Corresponding author. Tel.: +381 11 2636994; fax: +381 112185263 .

E-mail address: olivera.milosevic@itn.sanu.ac.rs (O. Milošević).
}

High luminescence efficiency is basically associated with high radiative transition rates which can be achieved with optimum doping concentration, uniform distribution of the luminescent centers in the host matrix and the overall particle structure and morphology control, which altogether signify the importance of innovative and controllable UCP phosphor processing route in the current research efforts [7-9]. Moreover, of particular importance is the controlled synthesis of the host lattice having targeting crystal structure which determines the distance between the dopant ions, their relative spatial position, their coordination numbers, and the type of anions surrounding the dopant. In addition, the low symmetry and low phonon energies of the host lattice are essential for reducing the multiphonon relaxation and increasing the lifetime of the intermediate states involved in upconversion [10]. Most of research are concerned with halide host matrix processing and particularly with the hexagonal sodium yttrium fluoride which has been regarded as one of the most efficient up conversion host matrix having the phonon energies below $500 \mathrm{~cm}^{-1}$ [11-13]. Of the medium phonon energies host matrices, cubic yttria posses high chemical and thermal stability and is one of the most efficient non-halide host material [11].

Among the diversity of the "bottom-up" chemical approaches for nanomaterials processing, synthesis through dispersion phase (aerosol) enables generation of ultrafine, either single or complex powders with controlled stoichiometry, chemical and phase con- 